\title{
Must schools teach religions neutrally? The Loyola case and the challenges of liberal neutrality in education
}

(Forthcoming in Religion \& Education)

Andrée-Anne Cormier

\begin{abstract}
This article explores the question of whether it is morally permissible for the liberal state to require schools to teach religions "neutrally" to children. I examine this question through the normative analysis of Canadian Supreme Court case Loyola High School v. Quebec. I argue that it is in principle morally impermissible for the liberal state to oblige all schools to adopt a neutral approach to teaching children about religious diversity. I propose a normative framework for evaluating the legitimacy of such an imposition and identify a strategy in support of accommodating schools like Loyola that does not appeal to the existence of a strong parental right to control their children's education.
\end{abstract}

Citizens, educators, and philosophers alike largely agree that schools should educate children about cultural and religious diversity in contemporary pluralistic societies. There is considerable disagreement, however, on how schools should approach this task, and more generally, who should control children's education. Consider the following two models of education that schools may adopt. First, they may educate children about a range of views, while at the same time treating their parents' own view as superior or true. Second, they may educate children about a diversity of views while remaining neutral as to which (if any) is superior or true. ${ }^{1}$ This article explores the question of whether, and under which conditions, it is morally permissible for the liberal state to directly sponsor, promote and/or oblige schools to adopt the second "neutral" approach to educating children about religions. I examine this question through the normative analysis of a recent Canadian Supreme Court case, Loyola High School v. Quebec, which challenges the legitimacy of such a model, as recently adopted in Quebec.

Since 2008, all of Quebec's primary and secondary schools are required to teach the course "Ethics and Religious Culture" (ERC) from a strictly secular perspective. The Quebec government has thus opted for a strong 
compulsory program of common schooling for all children; one that not only imposes a set of common educational goals, but also a specific curriculum content, focusing on ethics and religions, and a unified approach (defining the means) to teaching that content, namely, the so-called neutral, secular approach. Loyola High School, a private Jesuit school for boys in Montreal, asked to be exempted not from teaching the program altogether, but rather from the particular obligation to teach it while remaining neutral vis-å-vis their own religious perspective. Instead, Loyola asked to be allowed to teach the course from a Catholic perspective. ${ }^{2}$ In support of this demand, Loyola's defenders suggested, among other things, that the latter imposition cannot be justified, because teaching neutrally is impossible in practice and because the ERC program itself is in any case not neutral, for it cannot be defended on neutral grounds.

Loyola's objections are especially serious from a normative liberal perspective. Most political philosophers in contemporary liberal political thought, most notably political liberals (or public reason liberals) in the tradition of John Rawls (1993, 2003), defend a principle of state neutrality. From a Rawlsian political liberal point of view, if it is true that the program is nonneutral, at least in the particular sense that its justification presupposes the truth of a specific and reasonably controversial worldview, then it should indeed be seen as illegitimate. This implies that, by both sponsoring and imposing such a program, the state would not make morally acceptable use of its coercive power. As a matter of fact, philosopher Kyla EbelsDuggan reaches a similar conclusion from a more general perspective. She argues that because teaching can never be genuinely neutral in the morally relevant sense, and because the liberal state must indeed be neutral, the liberal state should simply not be a direct provider of education at all. According to her, there should be no state-sponsored public schools. Rather, a consistent political liberal position recommends adopting the first model of education above, within a general system of school choice. Constitutional law scholar Michael W. McConnell (2002) and philosopher Kevin Vallier (2014) also defend the same view, based on similar arguments.

This article offers a normative philosophical analysis of the Loyola case from the point of view of the political liberal principle of state neutrality. The fundamental question guiding my inquiry is then the following: Does the liberal principle of state neutrality (which I shall specify in detail below) imply that it is morally acceptable for the state to sponsor, promote and/or impose a secular, neutral, approach to educating children about religious diversity?

I defend the position that although the liberal state's sponsoring of a neutral approach to teaching religions is legitimate (contrary to what EbelsDuggan maintains), its imposition on all reluctant schools is problematic. 
I propose a normative framework for evaluating the legitimacy of such an imposition. Importantly, I also argue that the case for accommodating some religious schools, like Loyola, can be made (a) without appeal to the existence of a robust parental right to transmit their own worldview to their children or to extensively control their children's education and (b) even if we think that the burden of proof to show that an alternative program is adequate falls on the reluctant parent or school, as I shall suggest it does.

The ERC program and the Loyola high school case

In September 2008, the Quebec Ministry of Education introduced a new compulsory course on ERC in the public education curriculum. Since then, all children have to attend a continued training in ERC from the beginning of elementary school to the end of high school (in both private and public schools), for an overall period of 11 years. This program replaces the previous policy, dating back to 1984 , which gave parents the choice between, on the one hand, a course of "moral and religious catholic education" or "moral and religious protestant education" and, on the other hand, a course of "moral education" tout court. The choice between confessional religious education and non-confessional moral education within the public schooling program has thus been completely abolished in favor of a single, nonconfessional and unified training in ERC, offered to all children in all schools, independently of their parents' religious or moral beliefs and independently of the schools' religious orientation.

The course is conceived as an affirmation of secularism and state neutrality vis-å-vis all religions. ${ }^{3}$ From a historical point of view, its introduction is part of a broader process of secularization of Quebec's institutions, which has been taking place in the province roughly since the so-called Quiet Revolution in the 1960s. The ambition is to teach religions from an historical and cultural point of view, rather than a confessional and moralizing one. The main goals of the program are political in nature. More specifically, the program aims at contributing to harmonious social relations in today's pluralistic Quebec society by facilitating and promoting the recognition of others and the pursuit of the common good. According to the program, the realization of these goals requires the development of three key competencies in children/future citizens, namely, the abilities to reflect on ethical questions, to demonstrate an understanding of the religious phenomenon, and to engage in dialogue. ${ }^{4}$

The program has led to two Supreme Court cases, including Loyola High School v. Quebec. ${ }^{5}$ Here are some of the key facts about it. The case involved, on one side, Loyola High School and John Zucchi-a parent of a 
child attending the school - and, on the other side, the Quebec Ministry of Education. Loyola's request was essentially to be allowed to teach its own Catholic version of the program, instead of the official, secular version. The Supreme Court identified two key respects in which Loyola's proposed program indeed diverged from Quebec's generic version: "First, Loyola proposes to teach Catholicism from the Catholic perspective. Second, while ensuring that all ethical points are presented and encouraging students to think critically, Loyola proposes an approach that emphasizes the Catholic point of view when discussing ethical questions. In both respects, Loyola's teachers would depart from the strict neutrality required under the ERC Program." 6

Paul Donovan and Fr. Rob Brennan, S.J.-respectively, Loyola's school principal and its (former) President—offered two main reasons in support of Loyola's request for special exemption. The first was that the ERC program is incompatible with the religious convictions conveyed by Loyola and with its mission as a Catholic institution. Indeed, according to them, "the methodological 'neutrality' proposed by the $[\ldots]$ program $[\ldots]$ implies a moral relativism that contravenes the beliefs of many people and religions, including Catholicism [and] is also unrealistic and impossible to achieve in practice" (Loyola High School v. Courchesne, 2010: 10).

Douglas Farrow, a recognized expert in religion and theology heard as a testimony by the Superior Court of Quebec, supported this argumentative line. Farrow insisted on the idea that the ERC program's ultimate aim is not only to inform, but also, more ambitiously, to form students, by transmitting specific "norms"- something he took as an indication of non-neutrality. Farrow also denounced the program for allegedly being based on the (non-neutral) philosophy of "normative pluralism".

[W] hat is at issue is whether the pluralist philosophy [ $\ldots]$ should be imposed upon those who do not share it or think it sound; and whether the hegemony of pluralism, backed by government fiat, should extend even into the realm of religious schools. [...] All that needs to be said here is that its imposition cannot be justified in the name of some putative 'neutrality' that is characteristic of pluralism. Pluralism is not neutral, nor $[\ldots]$ is the ERC program that has taken pluralism as its foundation. (Farrow, 2010: 6)

The second main reason in favor of Loyola's request, offered by its representatives and defenders, is that the school's own alternative program is "equivalent" to the ERC program, because it fully embraces the key normative goal of promoting tolerance and respect for all, regardless of individual beliefs or values. In fact, Loyola's representatives claimed that their program goes even beyond this, for it teaches that "each human being, regardless of race or religion, is created in God's image and is therefore 
imbued with dignity and a value requiring not only respect for but love of all" (Farrow, 2010: 8).

The Supreme Court of Canada sided with Loyola on March 19, 2015.

\section{Liberal neutrality: an ambiguous ideal}

In this and the following sections, I shall assess in detail the arguments advanced by Loyola's defenders in light of the philosophical literature on political liberal neutrality and political legitimacy. As mentioned above, liberal theorists should take very seriously Loyola's central claim that the ERC program is non-neutral, since state neutrality is typically considered a condition of political legitimacy. The notion of neutrality, however, is seriously ambiguous and indeed admits several alternative interpretations. As John Rawls, the most famous defender of liberal neutrality, rightly observes: "[t] he term neutrality is unfortunate; some of its connotations are highly misleading, others suggest altogether impracticable principles" (Rawls, 1993: 191). It is unsurprising, then, that that the idea of state neutrality is the object of much confusion, both in academic and in political debates. Importantly, however, state neutrality matters for political legitimacy only in a narrow and very specific sense, according to most of its liberal defenders. It is thus crucial to be clear about what kind of neutrality is required for political legitimacy, so as to be able to pinpoint the specific sense in which the ERC program would have to be non-neutral to qualify as illegitimate from a normative political liberal perspective.

Let me start, first, by briefly clarifying the key notion of political legitimacy and highlighting some limitations of my inquiry in this article. The notion of political legitimacy refers to a state's (or a government's) moral right to exercise authority over its citizens. More specifically, it refers to the state's moral right to impose binding duties on its citizens and to use some degree of coercion to enforce their compliance with these duties (Simmons, 1999: 746; Quong, 2011: 108). A particular conception of political legitimacy specifies the conditions under which is it morally permissible for the state to exercise power over its citizens via laws or public policies. Liberal neutrality, in the sense I will soon specify, is typically seen as a necessary condition of political legitimacy so understood. It is important to keep in mind, however, that (a) there may be other necessary conditions of political legitimacy (e.g., having to do with democratic procedures), and that (b) besides legitimacy conditions, there may be other morally relevant considerations for the liberal state to take into account in designing public policies and making decisions about which groups to accommodate or exempt from certain policies (e.g., having to do with political stability or improving the situation of the worst off in society). This article, therefore, should not 
be seen as offering an all-things-considered normative analysis, but as focusing mainly on (one of) the most fundamental normative challenge raised by the Loyola case: that of liberal neutrality. Let me now turn to the task of specifying what kind of neutrality is a necessary condition for political legitimacy.

Political philosophers typically distinguish three forms of neutrality: justificatory neutrality, neutrality of effects, and pure procedural neutrality or neutrality of ground (Kymlicka, 1991; Rawls, 1993: 191-194). A policy is neutral at the justificatory level only if its justification does not appeal to, or presuppose, the truth of any reasonably controversial conception of the good. Positively put, the idea is that a policy is neutral at the justificatory level only if it can be justified on the basis of reasons that all reasonable citizens could accept in their capacity as free and equal members of society. By contrast, a policy is neutral at the level of effects only if it does not favor some conceptions of the good, or ways of life, over others, either in the sense of making it more likely that some conceptions will obtain more adherents over time and/or in the sense of making it less costly for adherents to adhere to that way of life. Finally, a policy is purely procedurally neutral only if it is fundamentally grounded in principles that do not reflect any substantive moral values or beliefs.

Of all these forms of neutrality, only justificatory neutrality is taken to be essential for political legitimacy by liberal political philosophers such as Rawls (1971, 1993, 2003), Gaus (2009), Nussbaum (2011), and Quong (2011). The Rawlsian argument in favor of justificatory neutrality emerges from the combination of two fundamental ideas that are widely accepted in contemporary political philosophy and that shape many important debates in the field. The first, most basic, idea is that society should be conceived as a fair system of cooperation between free and equal members. This essentially means that no one has natural authority over any other. Political power is the power of the people. According to Rawls, what makes us equals is our capacity to form, adopt, and revise a conception of the good, that is, a conception of what makes a human life worth living. The second fundamental idea is that there exists reasonable disagreement among free and equal persons about the good, that is, about what is valuable in life, what weight we should assign to different values, and more generally, how we should live and conceive the world. For example, reasonable persons may disagree about which religion is true (if any), about the morality of drug use, about sexual morality, about the value of creativity, etc. More specifically, the claim here is that even decently competent, well-informed, and well-intentioned reasoners who share a commitment to the basic moral idea that all persons are free and equal from a political point of view may still profoundly disagree about the good. ${ }^{8}$ 
Now, if we accept the claim that reasonable persons so understood inevitably disagree about the good, then, according to political liberals, we are led to a principle of justificatory neutrality. Indeed, if persons are free and equal from a political point of view, it seems that they are owed a justification for the use of political power against them that they can accept from their own perspective. But if there is reasonable disagreement about the good, then the state cannot appeal to (or presuppose) the truth of a particular conception of the good in order to justify its actions, because such justification would simply not be acceptable from the perspective of some reasonable members of society. The result is that, to be legitimate, the actions of the state must be justified in a way that remains neutral about the good. ${ }^{9}$

Jonathan Quong (2004) summarizes the idea as follows:

[B]ecause reasonable people disagree about the good life, the state will have to eschew any appeals to conceptions of the good in justifying its core principles. Put another way, only public reasons - reasons that are acceptable to all reasonable citizens - can legitimate the coercive use of state power over its citizens. It is in this way, and this way only, that the state should remain neutral between competing conceptions of the good in liberal theory. (Quong, 2004: 233, italics added for emphasis)

From a political liberal perspective, then, the ERC program counts as illegitimate if it is non-neutral in the justificatory sense just specified. It should be clear, however, that the principle of justificatory neutrality is not itself neutrally grounded. Rawls is explicit on this point: "Justice as fairness is not procedurally neutral. Clearly its principles of justice are substantive and express far more than procedural values, and so do its political conceptions of society and person" (Rawls, 1993: 192). In fact, as we have seen, the principle of justificatory neutrality derives from minimal yet substantive philosophical commitments, namely, that persons are free and equal, that society should be conceived as a fair system of cooperation, and that there is reasonable disagreement about the good.

Not only do these minimal, yet substantive, non-neutral claims ground the principle of liberal neutrality itself, but their public promotion seems essential for the stability and health of the liberal-democratic regime. As Jocelyn Maclure and Charles Taylor put it:

A liberal and democratic state cannot remain indifferent to certain core $[\ldots]$ constitutive values of liberal and democratic political systems; they provide these systems with their foundations and aims. Although these values are not neutral, they are legitimate, because it is they that allow citizens espousing very different conceptions of the good to live together in peace. (Maclure and Taylor, 2011: 12)

Thus, it is perfectly consistent for defenders of liberal neutrality to maintain that the state should not remain neutral when it comes to promoting 
basic foundational liberal values via its educational policies. This explains why preeminent civic education theorists and liberal neutralists, such as Amy Gutmann and Stephen Macedo, explicitly reject the claim that the mission of public schools is to provide children with the skills and knowledge necessary for personal autonomy while at the same time completely refraining to "push them in a particular direction". As Macedo puts it, children should in fact be "pushed" in a direction, namely, encouraged to accept basic liberal ideals such as political respect for their co-citizens despite their differences (Macedo, 2000: 237-238). ${ }^{10}$

From these observations, we can immediately conclude, against Farrow (2010), that the mere fact that the ERC program's goal is not only to inform, but also, much more ambitiously, to form students by transmitting specific "norms" is in no way problematic, as such, from the point of view of liberal neutrality. Indeed, to the extent that the purpose of the ERC program is to create respectful democratic citizens prepared to live in a pluralistic society, its formative nature does not in itself compromise political legitimacy. Again, the most important question here is whether the ERC program can pass the liberal test of justificatory neutrality as specified above. I explore this question in the next sections.

\section{Can the ERC program be justified neutrally?}

The key argument in favor of the ERC program offered by its main authors and defenders (Ouellet, 2000, 2006; MELS, 2005; Leroux, 2008) is that teaching about religious diversity is important to prepare pupils for life and democratic citizenship in a pluralistic society, where they will inevitably interact with people adhering to different religious views. Like most liberal philosophers of education (e.g., Gutmann, 1987; White, 1990; Levinson, 1999; Brighouse, 2000; Macedo, 2000; Reich, 2002; Callan, 2004), the defenders of the ERC program also believe that the existence of significant sociocultural and religious diversity, which characterizes liberal-democratic societies today, amplifies the necessity of common education. One important reason why this is the case is that profound diversity may threaten the stability of liberal and democratic institutions by disfavoring allegiance to basic liberal-democratic values. That is because the existence of profound differences in citizens' worldviews and ways of life may increase the risk of mutual misunderstanding or social mistrust. In turn, misunderstanding and mistrust risks bringing about social conflicts, eroding social relations and rendering more difficult respectful democratic dialogue amongst citizens. It is largely to mitigate these risks that many liberal theorists emphasize the importance of common schooling programs. In Terence McLaughlin's words, common schooling policies carry "heavy burdens" (McLaughlin, 
2003): They should both respect and protect (reasonable) diversity and, at the same time, pursue the unifying goal of inculcating in all children the common virtues that are needed for respect, mutual recognition, and democratic dialogue. Teaching religions at school, as part of a liberaldemocratic common education program, can help students see that other people have "diverse sources of spiritual inspiration" and "how deep-seated religious traditions have evolved over time" (Reich, 2002: 198). Most importantly, it contributes to ensuring that children recognize that their own (or their families') views about religion are not the only ones and that many people holding a range of different views are nonetheless trustworthy and worthy of basic political respect. This seems especially relevant in light of the fact that religious differences sometimes are, and historically have been, one important source of social and political conflict.

Superficially, one might think that these ideas, which motivate and justify the adoption of the ERC program, presuppose the truth of a particular controversial comprehensive philosophical view and, as such, violate the liberal principle of justificatory neutrality. Recall that one of Douglas Farrow's claims is, indeed, that the ERC program is based on the philosophy of normative pluralism (which he also calls "pluralist philosophy") — a philosophy that some reasonable citizens may no doubt reject. Farrow's interpretation seems supported by the fact that appeal to pluralism does play a major role in the justification of the ERC program. In fact, the program's defenders explicitly talk about it as constituting an "education to pluralism" (education au pluralism; Leroux, 2008, 2016). However, just like the notion of neutrality, the notions of pluralism or of a pluralist philosophy are ambiguous and are often used to refer to different ideas. To dissipate the worry that the ERC program presupposes a commitment to the philosophy of normative pluralism, then, it is worth distinguishing various meanings of pluralism or pluralist philosophy, as well as pointing out the difference between normative pluralism and moral relativism, which Loyola's defenders also believe the ERC program to promote.

There are at least two variants of normative pluralism, conceived as a philosophical view. Normative pluralism may refer to the idea that there exists a plurality of moral principles, that is, principles that tell us which actions are right and wrong. Or it may refer to the idea that there exists a plurality of final values, that is, a plurality of things that are valuable for their own sake, such as, for example, happiness. The former contrasts with monism about moral principles, according to which there exists a single fundamental criterion of rightness and wrongness. The most obvious example of a monist moral theory is utilitarianism, according to which an action is morally right if and only if it maximizes happiness in the world. Value pluralism, in turn, contrasts with value monism, according to which 
all values are reducible to one "supreme value," for example, happiness, ultimately conferring value to all other valuable things. ${ }^{11}$ It is worth pointing out that when we talk about pluralism in everyday life and political discourse, we often do not have in mind any normative philosophical view. We often simply have in mind an empirical fact characterizing contemporary liberal-democratic societies, namely, that different individuals and groups adhere to a wide range of different worldviews, lead different kinds of lives and value a range of diverse things to various degrees. This is what we may call descriptive pluralism, which of course has nothing to do with normative pluralism. Finally, normative pluralism should also not be conflated with moral relativism. Moral relativism is primarily a meta-ethical theory according to which there is no objective moral truth, that is, there is no objective standard in light of which different moral practices or beliefs can be evaluated and compared. ${ }^{12}$

With these distinctions in place, we can now see that the justification for the ERC program does not imply or presuppose a commitment to any version of either normative pluralism or moral relativism. In fact, it is perfectly compatible with the rejection of any of these views. The justification for the program does rely on an ideal of respect for reasonable pluralism, more specifically, respect for persons adhering to various worldviews different from one's own. But even though the ideal of respect for pluralism is not itself neutral (as we have seen above), accepting it does not require accepting either normative pluralism or moral relativism. In fact, one may consistently believe that all persons are worthy of fundamental political respect, and that all should be able to live their lives in accordance with their own convictions (at least provided that they respect others' freedom to do the same), while at the same time believing that only one conception of the good or religious view (their own) is objectively true and that only one way of life is objectively valuable. Believing this implies denying both moral relativism and normative pluralism. Just to give one more concrete example, one may strongly believe that there exists a universal truth about religious beliefs (e.g., that they are all false and that the lives of religious believers are based on an illusion), while also firmly believing that all religious believers are fully equal members of society who should be respected and accommodated politically. ${ }^{13}$ Religious believers may coherently believe the same thing about atheists.

There is thus no incompatibility, or even a tension, between the ideal of respect for pluralism as just specified, and Loyola's representatives' own religious commitments. After all, they believe that "each human being [ ... ] is imbued with dignity and a value requiring not only respect for but love of all" (Farrow, 2010: 8). So, can we then conclude that the ERC program passes the political legitimacy test? Not quite. That is because the previous 
considerations show simply that the goals of the ERC program are legitimate. Crucially, however, they do not show that the means proposed, and indeed imposed, by Quebec to fulfill such goals are acceptable. Yet, this is what Loyola's representatives ultimately contest, namely, the particular way in which the ERC program proposes to achieve its (legitimate) goals. So, we need to investigate more specifically whether the imposition of a neutral approach to teaching about religious diversity can be justified.

An objection from the impossibility of neutral teaching

Recall Donovan and Fr. Brennan's first argument in favor of Loyola's request for special exemption. After claiming that "the methodological 'neutrality' proposed by the $[\ldots]$ program [ ...] implies a moral relativism that contravenes the beliefs of many people and religions, including Catholicism," Donovan and Fr. Brennan argue that such a neutral approach "is also unrealistic and impossible to achieve in practice" (Loyola High School v. Courchesne, 2010: 10, italics added for emphasis). Similarly, they suggest that "[t]he practical result of [neutrality] is a kind of individual relativism in the context of state agnosticism that understands truth as something residing entirely within each individual with the state presenting the view that religious truth cannot be really known or judged" (Donovan et al., 2011).

As we have seen, the charge that the ECR program requires accepting the truth of moral relativism (or normative pluralism) is unwarranted. There remains to consider the charge that neutral teaching is impossible in practice. Although there are different ways of interpreting this charge and the other concerns expressed by Loyola's defenders in the quotes above, they point to one particularly serious objection that can be made against the ERC program. I will illustrate this objection by reference to an argument recently proposed by philosopher Kyla Ebels-Duggan (2013).

Ebels-Duggan challenges the legitimacy of a state-sponsored neutral approach to teaching about diversity on the ground that teaching can never be truly neutral in the normatively relevant sense. More specifically, she claims that presenting different views to students neutrally is equivalent to presenting them "as on an evaluative par," which in her view, inevitably conveys a nonneutral message to them. More specifically, her argument is the following. First, she observes that, in teaching different worldviews, a teacher can only choose between two possible approaches: she can either present them "as on an evaluative par" with one another or present some "as superior to others." Clearly, as Ebels-Duggan points out, the latter is not an acceptable option from the point of view of liberal neutrality. The reason is that reasonable citizens could obviously reject educational policies 
that communicate the superiority of worldviews to which they are reasonably opposed. However, she argues, the alternative approach is equally problematic from the point of view of liberal neutrality. This is because, by presenting different moral or religious views "as on an evaluative par," teachers inevitably end up communicating the idea that such views are just matters of personal preferences. The problem, she claims, is that many reasonable citizens (e.g., religious ones) see their own moral or religious commitments as nondiscretionary, and they understand their obligations as parents to include the transmission of such commitments to their children. They could therefore reasonably reject an educational approach that is so starkly in contrast with their convictions. As she puts it,

Most everyone thinks that some matters are appropriately regarded as evaluatively discretionary while others are not. But, and this point is of central importance, which matters are evaluatively indifferent is itself an important, difficult and controversial normative question. This is just the sort of question over which reasonable citizens will persistently disagree. Many parents take themselves to be obligated to help their children get these matters right. (Ebels-Duggan, 2013: 48).

So, according to Ebels-Duggan, given that teaching neutrally involves teaching evaluative parity, the liberal state cannot permissibly promote such an approach, let alone oblige reluctant schools to adopt it. Indeed, adopting such an approach to teaching about religious diversity amounts to promoting a conception of religion that is antithetical to the beliefs of many reasonable religious citizens. This cannot be justified from the point of view of those citizens. As such, the neutral teaching approach implies a violation of justificatory neutrality. Ebels-Duggan's thereby concludes that, since neither of the two approaches available to teachers in state schools is legitimate from a political liberal point of view, it follows that the liberal state should not be a direct provider of education at all. State-operated and state-sponsored schools should simply be abolished in favor of a system of school choice for all parents. ${ }^{14}$

Ebels-Duggan's argument is especially relevant for the case under consideration. If her argument is correct, the implications for the Loyola case are radical. Her argument not only supports the idea that Loyola should be accommodated; it actually supports the idea that the ERC program and indeed public schools themselves should be eliminated. It is thus important to assess the merits of Ebels-Duggan's position.

A first problem with Ebels-Duggan's argument is that it seems to assume that parents have a fundamental right to shape their children's values in light of their own, provided that they are reasonable citizens. In other words, her argument appears to rely on the idea that if parents endorse a reasonable worldview, then it is permissible for them to transmit such view to their children. But this is far from clear from a liberal perspective. The 
existence of such parental right does not immediately follow from the fact that the parents' view is reasonable. After all, no one thinks that the fact that one's view is reasonable gives one a right to impose that view on other adults, say on a lover or a friend. Surely, the fact that many (young) children do not qualify as autonomous, unlike most of our fellow adult citizens, is normatively relevant. Yet, children are equal members of society, and the issue of how authority over them should be divided between parents, the state, teachers, and other adults does not admit of any obvious answer. There is no straightforward or obvious connection between 'holding a reasonable view' and 'having a right to transmit it' to one's children. ${ }^{15}$ This potentially represents a serious challenge for Ebels-Diggan's view, because if parents do not have a fundamental right to try and transmit their comprehensive worldviews to their children, then the fact that an educational program conflicts with some parents' conception of their parental duties no longer clearly provides a sufficient reason to reject such program.

Be that as it may, even assuming that parents have such strong parental rights, there are still other difficulties with Ebels-Duggan argument. To begin with, it must be observed that if religious beliefs were indeed presented to children (implicitly or explicitly) as akin to mere preferences, such as preferences for a particular ice cream or a particular dress, then not only would liberal neutrality arguably be compromised, but the goals of the ERC program as well would plausibly be undermined. Indeed, presenting religious beliefs in this way would potentially have the effect of trivializing them. By so doing, the program would fail to teach children about the nature of religious beliefs as many (perhaps most) religious believers conceive of them. By portraying the beliefs of religious citizens in such inauthentic and misleading ways, the program would likely fail to effectively achieve the goal of promoting mutual respect and democratic dialogue. That is because some children (particularly the nonreligious onesthe majority in Quebec) would likely fail to understand the special importance that some of their fellow citizens assign to their religious commitments. They would thereby also likely fail to see that, for example, accommodating religious practices is not morally equivalent to accommodating a mere (nonidentity defining) preference.

That being said, the crucial questions that we need to consider are the following. First, is it true that presenting religious beliefs neutrally involves, or results in, presenting them "as on an evaluative par," as Ebels-Duggan maintains? Second, assuming that this is the case, is it true that this inevitably involves presenting them as mere discretionary objects of personal preference? Let us start from the second question. Saying that two views are on an evaluative par is equivalent to saying that there is no sufficient 
reason for endorsing one rather than the other. In this sense, choosing one of these views might be a matter of personal preference. Even so, however, it would not follow that choosing between these views would be fully discretionary or a trivial matter. The opposite conclusion holds only if one treats all personal preferences as akin to tastes, that is, to things for which no reason can be asked or which plays no important role in shaping one's identity. However, this is not true of all sorts of preferences, or views or commitments. In at least some cases, forming a "preference" between two views that are on an evaluative par may require one to fully appreciate the reasons that support each of those views and to understand the significance that such reasons may have for one's overall commitments and identity. When that is the case, choosing between two views is no longer a matter of 'mere' personal preference. This is certainly true in the case of many religious beliefs, and it is also true in the case of "preferences" for those we love, for our country, for some cultural norms. Contrary to what EbelsDuggan implies, then, it is not the case that presenting religious views as matters of personal preference necessarily involves presenting them as fully discretionary. The teacher would clearly have an important role to play in distinguishing the case of moral and religious beliefs and commitments from other cases involving matters of mere taste. Although difficult, this is not an impossible task for them to accomplish.

Another objection to Ebels-Duggan's argument consists in denying that presenting religious beliefs neutrally involves presenting them as on an evaluative par. This objection can be expressed by considering an analogy with the teaching of philosophy. Many philosophy teachers choose to present different philosophical views neutrally in the classroom, in the sense that they treat each view as charitably as possible, do not reveal to their students which theory they think is true or best, seek not to influence their students into endorsing one view or another and encourage them to make their own minds on the issue being discussed. At the same time, most philosophy teachers actively seek not to convey the message that philosophical beliefs and theories are mere matters of personal preferences or that all philosophical views are equally plausible or good. In other words, although they present different views as if they were on an evaluative par, they make sure to convey the message that that such views are not actually on an evaluative par. Now, it is hard to deny that at least some teachers succeed both in remaining neutral in this sense and at the same time in communicating to their students the 'right' message about the nature of philosophical inquiry. I see then no reason to think that something similar cannot be done also in teaching religions.

If all this is correct, it follows that, contrary to what Ebels-Duggan maintains (and Donovan and Fr. Brennan suggest), it is possible to successfully 
teach about religious diversity without communicating to students a problematically non-neutral message about the nature of religious beliefs as some reasonable citizens conceive of them. If so, it also follows that it is permissible, at least in principle, for the state to sponsor or promote the neutral teaching of religious culture. Thus, the strongest objection against the ERC program, and against state-sponsored public schools tout court, fails. At the same time, it must be noted that there is a difference between publicly sponsoring or promoting an educational approach, and legally imposing it on all schools. None of what has been said so far implies that the state can legitimately impose such an educational approach on all reluctant schools. To see whether this is the case, we need to examine in more detail Loyola's second argument in support of its demand for accommodation (i.e., the argument according to which its own version of the ERC program is relevantly equivalent to the state's version). This argument raises at least two crucial normative questions: What constitutes normatively relevant equivalence? And on whom does the burden of proving equivalence fall? I will consider these questions in the next section.

\section{Equivalence and the burden of proof}

Loyola's representatives emphasized the fact that their alternative program embraces the core goals of promoting respect for all, regardless of individual beliefs or values. Like the ERC version, Loyola's program is also explicitly committed to facilitating the development of children's autonomy in that it encourages students to "think critically" and "examine popular beliefs and practices."16 However, the fact that Loyola's program embraces similar key goals does not necessarily imply that it really is equivalent. There are at least two morally relevant ways in which, despite embracing similar goals, Loyola's program may be inferior to the secular version. First, it may be less effective at achieving the same crucial normative goals. Second, it may undermine (or conflict with) some other duties of justice that the state may have towards children or other citizens.

To figure out whether a program is problematic in second sense, we would need a full-blown account of state duties - which is clearly beyond the scope of this article. Thus, in what follows, I will focus mostly on the first sense in which Loyola's program may be seen as problematic, namely, with respect to its capacity to effectively achieve its normative purposes. In my view, the efficiency issue raises, indeed, a key question concerning the burden of proof.

To begin with, let us observe that whether and to what extent Loyola's program - or the state's, for that matter - may successfully achieve its key normative goals is largely an empirical question. In other words, to assess 
the effectiveness of Loyola's program in relation to the key normative purposes it embraces, we need relevant empirical evidence. The problem is that, in the context of policy-making, we often lack much of the relevant evidence. And when some relevant evidence is available, it is often messy, incomplete, or contested. This leads to the following question. When parents (and schools) disagree with the state about the most desirable and appropriate means for achieving some important educational goals (over which they agree), on which party falls the burden of proof? Must the state provide the reluctant parent or school with sufficient evidence that the secular, neutral educational approach is superior (and sufficiently so to justify coercion)? Or does the corresponding duty fall on the reluctant parent or school?

The burden of proof question is particularly tricky in the context of education policies, in a way that has not been sufficiently acknowledged in liberal thought. Generally speaking, it appears to follow from the recognition that people are free and equal that it is the party that has (asymmetric) coercive power vis-ä-vis the other that should demonstrate that any exercise of such power is justified. That party is typically the state, and the individuals subjected to such power are its citizens. Where children's education is concerned, however, there is a special difficulty. Although parents are subject to the coercive power of the state, children are subject to the coercive power of both the state and their parents. The parent-child relationship is indeed nonvoluntary and coercive for children. Children cannot consent to being in a relationship with their parents. Furthermore, unlike in most adults' relationships, children do not typically have the capacity to exit their relationship with their parents. In brief, parental power over children seems coercive and pervasive in ways that are similar to the state's power over its citizens. ${ }^{17}$ This generates a unique puzzle. As said above, we normally think that the burden of proof falls on the party in a position of coercive power. But there are two different parties in that position vis-å-vis children. So, it is not clear on whom the burden of proof falls, for what decisions, and when.

It may seem that there is an easy solution to this puzzle. Intuitively, it seems that the presumption of legitimate authority over children should always be in favor of parents, because parents obviously care more deeply about their children than the state. In fact, most parents identify with their role as parents at the deepest level. So-the argument goes-whenever there is disagreement between parents and the state over children's education, it falls on the state to show that it is permissible to limit parental freedom. The problem is that the mere fact that parents care more deeply about their children and profoundly identify with their parental role cannot conclusively support a strong presumption in favor of parental authority. To see 
this, it is sufficient to note that no one thinks that individuals should have the freedom to extensively control the lives of other adults simply because they deeply care about them or are engaged in a loving relationship with them. It is not clear why, and to what extent, things should be different when children are concerned, at least if we take seriously the idea that children are free and equal members of society in some meaningful senseand not an extension of their parents' selves, unlike what Robert Nozick famously suggested. Rather, if we consider the fact that children have very powerful interests of their own, which surely grounds important limitations on parents' freedom to control their lives in line with their convictions, it seems plausible to say, at a minimum, that the presumption of legitimate authority should not always be in favor of parents. More specifically, there should arguably be no presumption in favor of parents over the state when parents propose extensive exercise of control over their children, for instance, beyond the home and into the sphere of schools.

I think that the previous considerations provide support to the idea that, in cases like Loyola's, the burden of proof might fall more heavily on the side of the reluctant parents or schools. However, this does not at all imply that exemptions should never be granted to reluctant parents or schools. If the burden of proof indeed falls on the parental side, we can only conclude that, to justify its case, Loyola would have to satisfy a more demanding test than if the burden of proof felt on the state. In light of what has been said so far, it seems that the relevant normative test would consist in providing sufficient evidence to the effect that the alternative program is (a) at least equally likely to achieve the same key goals as the state's program; and (b) does not present the risk of coming at greater costs than the state's program in terms of other weighty demands of justice. If evidence supporting these claims can be provided, then the state loses its presumptive right to limit the freedom of parents via its schooling policies. Assuming that my proposed test is plausible, the question becomes: Can Loyola actually satisfy the two conditions? Although I do not have the space to provide a full defense of a positive answer, let me point to what I take to be the best strategy available to Loyola, particularity with regard to satisfying condition (a).

To being with, it should be noted that (a) is a comparative condition. Loyola must provide evidence that its proposed program is at least as likely as the state's version to achieve its key normative goals. To do that, we need to consider whether teaching religions in a neutral way is, by itself, more likely to successfully promote respect for religious diversity than teaching respect for religious diversity from the perspective of a particular religion. I think there is good reason to be at least skeptical about the superior effectiveness of the neutral approach in this respect. On the one 
hand, when respect for diversity is taught from a particular religious perspective, a broader range of reasons can be proposed to children. Children are more likely, given their community ties, to directly identify with those particular reasons, and be moved by them. I have in mind reasons in support of respect for diversity that are given by a comprehensive perspective such as the Jesuit perspective, in the Loyola case. On the other hand, while teaching about religious diversity in a neutral way is possible (as shown above in response to Ebels-Duggan's argument), it is nevertheless very hard to do it well. In fact, it is very easy to imagine that, in the process of trying to teach in an appropriately neutral way, a teacher might either unintentionally send a non-neutral message about the nature of religious beliefs or unintentionally increase the likelihood that children will in effect end up endorsing a moral relativist stance. ${ }^{18}$ I believe that, if warranted, the latter concern is a serious one from a liberal perspective. Indeed, if teaching neutrally comes at the risk of inadvertently promoting a moral relativist attitude, then it risks undermining the goal of successfully inculcating democratic liberal-values as well. As Amy Gutmann (1987: 56) puts it, the attitude "I have my opinion and you have yours and who's to say who's right?' [ ... ] does not take the demands of democratic justice seriously." That is because children's relativist attitudes may extend to basic liberal values themselves. If children adopt a moral relativist outlook, they might come to think, for instance, that respect for minorities or gender equality is just a matter of personal opinion, as plausible or worthy as any another view. This is clearly problematic from a liberal point of view. That said, it may be the case that the inadvertent promotion of a sort of moral relativism that is unfriendly to basic liberal values, if and when it occurs, is mostly the result of teachers' and policy makers' inadequate training and resources and/or misconceptions about demands of liberal neutrality in education. Yet, these sorts of difficulties may potentially support Loyola's case, at least provided that Loyola can point to evidence validating such concerns in the relevant contexts. If combined with evidence also supporting the first point mentioned above, according to which teaching respect for diversity from a religious perspective may provide extra valuable resources to teachers, the case in favor of accommodating Loyola becomes strong. This is a significant, and perhaps surprising, result because it implies that a conclusion favorable to Loyola can be reached even within a normative framework that denies the existence of very robust parental rights and freedoms. More specifically, Loyola's case can be defended even within a normative framework that does not presume or accept the existence of a fundamental parental right to control their children's schooling experience in light of their comprehensive values, or to shape their children's comprehensive values or religious commitments in light of their own. 


\section{Conclusion}

In this article I considered the two main arguments proposed by Loyola's defenders and representatives in favor of their case and against the ERC program. The first is that the latter is not neutral in a way that is problematic from the point of view of political legitimacy. The second is that Loyola's own program is relevantly equivalent to the state's program. In response to the first objection, I argued that the justification for the ERC program does not require any commitment to normative pluralism or moral relativism, and that neutral teaching is possible in practice. In response to the second line of argument, I offered some reasons to believe that the burden of showing that their program is genuinely equivalent falls on Loyola. At the same time, I also suggested that Loyola might be able to successfully take on this burden. If what I have said is correct, then the upshot is, on the one hand, that it is permissible for the state to sponsor a neutral approach to teaching diversity, and, on the other hand, that the Supreme Court's decision to grant Loyola's request of accommodation was indeed justified. Ultimately, I hope to at least have provided a normative recipe for building a case in favor of accommodating some schools like Loyola, which does not rely on any strong presumption in favor of parental freedom to transmit their own views to their children or extensively control their children's education.

\section{Acknowledgments}

I had the chance to discuss the issues addressed in this article with more people than I can probably remember. For useful comments on recent drafts or presentations of the article, I am grateful to Serena Olsaretti, Jonathan Quong, Mauro Rossi, Harry Brighouse, Daniel Weinstock, Meira Levinson, Kyla Ebels-Duggan, Kristin Voigt, Michele Palmira, François Boucher, Gina Schouten, Kevin McDonough, Sarah Stroud, Christine Tappolet, Sarah Hannan, Erik Magnusson, Riccardo Spotorno and Jacob Fay. I completed this article when I was a postdoctoral fellow at the Universitat Pompeu Fabra, in Barcelona, working as a member of the Family Justice research project, funded by the European Research Council and led by Serena Olsaretti. I am grateful to Serena and all the members of the Family Justice group for providing me with an exceptionally rich and supportive research environment.

This project has received funding from the European Research Council (ERC) under the European Union's Horizon 2020 Research and Innovation program [Grant Agreement Number: 648610]. 


\section{Notes}

1. In principle, we can identify at least three other models of education (see Kyla EbelsDuggan, 2013), in addition to the two mentioned above, but which seem more clearly objectionable from a liberal point of view. Schools may educate children exclusively within their parents' worldview, without transmitting knowledge about other worldviews, values, and ways of life. Schools may educate children within a single specific worldview (e.g., a particular religion) chosen by the state. Finally, schools may simply avoid discussing religious diversity or any socially divisive or controversial topics or views. (Note that the latter option is objectionable on the grounds that learning to respectfully discuss and engage with sociocultural and religious diversity, and socially controversial issues, seems to be a key aspect of a good liberal-democratic citizenship education.)

2. Loyola originally asked to be able to teach the entire program from a Catholic perspective, including other religions. Before the Supreme Court of Canada, however, Loyola revised its position and asked only to be allowed to teach "Catholic doctrine and ethics from a Catholic perspective”. See Loyola High School v. Quebec (Attorney General), 2015, SCC 12, paragraph 31.

3. See Bouchard, G. and Taylor, C. (2008), Leroux, G. (2008), Maclure, J. and Taylor, C. (2011) and Loyola High School v. Quebec (Attorney General), 2015, SCC 12

4. See Ministẻre de l'Éducation, du Loisir et du Sport (2005).

5. The other case is S.L. v. Commission scolaire des Chenes (2012). This case involved, on the one hand, a coalition of catholic parents and, on the other hand, a school board in the city of Drummondville and the Attorney General of Quebec. The religious parents (S.L.) requested that their children be fully exempted from attending the ECR course. In particular, they argued that "the ERC Program is not in fact neutral and that students following the ERC course would be exposed to a form of relativism which would interfere with their ability to pass their faith on to their children" (S.L. v. Commission scolaire des Chenes, 2012: 5). The Supreme Court ruled against the parents on February 17, 2012.

6. Loyola High School v. Quebec (Attorney General), 2015, SCC 12, paragraph. 128.

7. Farrow borrows the term from the philosopher Georges Leroux (2008), an important defender of the program.

8. The idea of reasonable persons is a normative notion. It indeed refers to an idealized idea of well-informed and competent reasoners who endorse the idea of society as a fair system of cooperation between free and equal members. As such, it does not refer to actual persons, although many actual persons qualify as reasonable. See Quong (2011).

9. The reason why the use of political power must be justified only to the narrow constituency of reasonable people is because, as Quong puts it: "[t]here are many ignorant, immoral, self-obsessed, or otherwise troublesome people in the world as we know it, and we do not want our political principles to be hostage to their unreasonable demands" (Quong, 2011: 37). This also explains why the group of reasonable citizens is itself a hypothetical, idealized, group of reasoners. See also Rawls, 1993: 48-71; Quong, 2011: 37-38, 142-145; Vallier 2014: 29.

10. As Amy Gutmann also notes, "If children come to school believing that 'blacks, Jews, Catholics, and/or homosexuals are inferior beings who shouldn't have the same rights as the rest of us,' then $[\ldots]$ criticism [ $\ldots]$ of children's values $[\ldots]$ is needed" (Gutmann,1987: 56). 
11. When value pluralism is concerned, another important (and overlooked) distinction is the one between internal and external value pluralism. Joseph Raz, one of the most famous defenders of value pluralism, characterizes "external" moral pluralism in terms of two claims. The first is that there is a plurality of morally acceptable, although incompatible, ways of life. The second is that these ways of life realize distinct values that can be "pursued for their own sake" (Raz, 1986: 369). External value pluralism is the opposite of "internal" value pluralism. According to it, there is a diverse range of intrinsically valuable goods, but only one good way of organizing them all; so only sort of life is truly good. As Martha Nussbaum notes, "[m]ost cultures, including religious cultures, are internal-pluralists: Internal pluralism is just a feature of any reasonably sane cultural view. It is difficult indeed to think of a morality that is genuinely monistic, reducing all the values to one, unless it be Benthamite Utilitarianism" (Nussbaum, 2011: 10).

12. Alternatively, it can be understood as a particular substantive normative theory, according to which what one ought to do (what is right) is entirely relative to either one's individual opinions (individual relativism) or to one's cultural norms (cultural relativism).

13. It may be the case that to be psychologically motivated to fully respect and accommodate the views of others, we need to recognize the existence of reasonable pluralism, more specifically, to recognize that disagreement would persist even at the high level epistemic idealization, such that we cannot simply attribute the different views of others to their ignorance or stupidity. (See Leland and Van Wietmarschen, 2012). As Kevin Vallier puts it, to recognize reasonable pluralism means: [...] to recognize that one's disagreement with her fellow citizens are not necessarily due to vice or ignorance on their part. Instead, she must be open to the fact that rational, well-informed and fair-minded persons may adhere to an ideal or philosophical doctrine entirely different from her own (Vallier, 2014: 89). Once again, however, to recognize reasonable pluralism in this sense is not equivalent to nor implies to accepting normative pluralism or moral relativism.

14. It may seem that such a strong conclusion does not follow from Ebels-Duggan's argument. What follows instead, one might suggest, is simply that we should leave religious education out of schools. I will not pursue this line of objection to EbelsDuggan here, but it is worth noting that Ebels-Duggan could resist it by saying that teaching children about religious (and other forms of) diversity is both inevitable and desirable for independent reasons. Insofar as this is the case, she might say, it should not be done by the state.

15. Clayton (2006), for instance, argues that parents have no right to deliberately try and transmit their religious views to their children, even if their parenting fully respects the development of their child's autonomy and sense of justice. I argue elsewhere that parents only have a very limited and conditional moral right to do so (Cormier, forthcoming).

16. Loyola High School v. Courchesne, 2010: 10.

17. See Clayton 2006 and Brighouse and Swift, 2014.

18. This is another way to interpret one of Loyola's defenders' concerns when they suggest that "[t]he practical result of [neutrality] is a kind of individual relativism".

\section{ORCID}

Andre̊e-Anne Cormier (D) http://orcid.org/0000-0001-6572-6935 


\section{References}

Amy Gutman. Democratic Education (Princeton: Princeton University Press, 1987).

Amy Gutmann, "Civic Education and Social Diversity," Ethics 105, no. 3 (1995): 557-79.

Andręe-Anne Cormier. "On the Permissibility of Shaping Children's Values," Critical Review of International Social and Political Philosophy, (Forthcoming). DOI: 10.1080/ 13698230.2017.1398481.

Daniel Weinstock, “A Neutral Conception of Reasonableness?," Episteme: A Journal of Social Epistemology 3, no. 3 (2006): 234-47.

Douglas Farrow, (2010). On the Ethics and Religious Culture Program. Report for Witness Expert. Cour Supe̊rieure, District de Montre̊al, No 500-17-045278-085.

Eamonn Callan. Creating Citizens, Political Education and Liberal Democracy (Oxford: Oxford University Press, 2004).

Fernand Ouellet, L'enseignement culturel des religions. Le dẻbat (Sherbrooke: Éditions du CRP, 2000).

Fernand Ouellet, (dir., Quelle formation pour l'enseignement de l'ęthique à l'êcole? (Quẻbec: Presses de l'Universite̊ Laval, 2006).

Gerard Bouchard, and Charles Taylor. (2008). Building the Future: A Time for Reconciliation. Report. Bibliothe̊que et Archives nationales du Que̊bec, Gouvernement du Quẻbec.

Georges Leroux, Éthique et culture religieuse: arguments pour un programme (Montrẻal: Fides, 2008).

Georges Leroux, Diffẻrence et liberte̊: Enjeux actuels de l'ẻducation au pluralisme (Montrěal: Les Éditions du Borẻal, 2016).

Gerald Gaus, "The Moral Foundations of Liberal Neutrality," In Contemporary Debates in Political Philosophy, edited by T. Christiano and J. P. Christman, (London: Wiley Blackwell, 2009).

Gilbert Harman, Explaining Value and Other Essays in Moral Philosophy (Oxford: Oxford University Press, 2000).

Harry Brighouse, School Choice and Social Justice (Oxford: Oxford University Press, 2000).

Harry Brighouse, and A. Swift. Family Values: The Ethics of Parent-Child Relationships (Princeton: Princeton University Press, 2014).

Jocelyn Maclure, and Charles Taylor, Secularism and Freedom of Conscience. Trans. Jane Marie Todd (Cambridge, MA: Harvard University Press, 2011). Originally published as Laïcite̊ et liberte̊ de conscience, Montre̊al, Borěal, 2010.

John Rawls, A Theory of Justice (Revised Edition) (Oxford: The Clarendon Press, 1971).

John Rawls, Political Liberalism (Expanded Edition) (New York: Columbia Classics in Philosophy, 1993).

John Rawls, Justice as Fairness: A Restatement (Cambridge, MA: The Belknap Press of Harvard University Press, 2003).

John Tomasi, Liberalism Beyond Justice. Citizens, Society and the Boundaries of Political Theory (Princeton: Princeton University Press, 2001).

John White, Education and the Good Life: Beyond the National Curriculum (London: Kogan Page, 1990).

John Simmons, "Justification and Legitimacy," Ethics 109, no. 4 (1999): 739-71.

Jonathan Quong, "The Scope of Public Reason," Political Studies 52, no. 2 (2004): 233-50. Jonathan Quong, Liberalism Without Perfection (Oxford: Oxford University Press, 2011). Joseph Raz, The Morality of Freedom (Oxford: Oxford University Press, 1986). 
Kevin Vallier, Liberal Politics and Public Faith: Beyond Separation (New York: Routledge, 2014).

Kyla Ebels-Duggan, "Moral Education in the Liberal State," Journal of Practical Ethics, 1, no. 2 (2013): 34-63.

Leland RJ, and Han Van Wietmarschen, "Reasonableness, Intellectual Modesty, and Reciprocity in Political Justification," Ethics 122, no. 4 (2012): 721-47.

Loyola High School v. Courchesne, 2010, QCCS 2631.

Loyola High School v. Quebec (Attorney General), 2015, SCC 12. Date: 20150319. Docket: 3501.

Marta Nussbaum, "Perfectionist Liberalism and Political Liberalism," Philosophy \& Public Affairs 39, no. 1 (2011): 3-45.

Matt S. Waldren, "Why Liberal Neutralists Should Accept Educational Neutrality," Ethical Theory and Moral Practice 16, no. 1 (2013): 71-83.

Meira Levinson, The Demands of liberal Education (Oxford: Oxford University Press, 1999).

Michael McConnell, "Education Disestablishment: Why Democratic Values are Ill-Served by Democratic Control of Schooling," in NOMOS XLIII: Moral and Political Education, edited by S. Macedo and Y. Tamir (New York: New York University Press, 2002), 87-146.

Ministe̊re de l'Éducation, du Loisir et du Sport (MELS), La mise en place d'un programme d'êthique et de culture religieuse. Une orientation d'avenir pour tous les jeunes du Québec (Quẻbec, Ministęre de l'Éducation, du Loisir et du Sport, 2005).

Ministẻre de l'Éducation, du Loisir et du Sport (MELS). Programme de formation de l'ẻcole quẻbe̊coise - Éthique et culture religieuse. http://www.education.gouv.qc.ca/fileadmin/ site_web/documents/dpse/formation_jeunes/EthiqueCultRel_Primaire.pdf

Paul Donovan, Suzanne Lavallee, Alain Gignac, Sylvain Fournier, Élisabeth Garant and Louis O'Neil. La religion sans confession. Regards sur le cours d'êthique et de culture religieuse (Montrěal: Médiaspaul, 2011).

Quẻbec (Procureur gẻne̊ral) v. Loyola High School, 2012, QCCA 2139.

Rob Reich, Bridging Liberalism and Multiculturalism in American Education (Chicago: The University of Chicago Press, 2002).

Stephen Macedo, "Liberal Civic Education and Religious Fundamentalism: The Case of God v. John Rawls?” Ethics 105, no. 3 (1995): 468-96.

Stephen Macedo, Diversity and Distrust. Civic Education in a Multicultural Democracy (Cambridge, MA: Harvard University Press, 2000).

S.L. v. Commission scolaire des Chenes, 2012, SCC 7.

Terence H. McLaughlin, "The Burdens and Dilemmas of Common Schooling," in Citizenship and Education in Liberal-Democratic Societies, edited by K. McDonough and W. Feinberg (Oxford: Oxford University Press, 2003), 121-56.

Will Kymlicka, Liberalism, Community and Culture (Oxford: Oxford University Press, 1991). 